\title{
SURFACE SLOPES AND ICE THICKNESS IN WEST ANTARGTICA
}

THE final paper was read by Dr. C. R. Bentley. In it he reported the results of attempting to correlate observations of surface slope and depth. The surface heights were found by altimetry and the surface slopes by theodolite observations, rejecting the slope readings from those places where the maximum slope to the horizon was not opposite in direction from the minimum. The depth measurements were obtained by seismic soundings.

No good correlation was found between surface slope and depth, implying that the shear stress on the bed varies considerably, and these variations in shear stress did not appear to be systematic. In particular over an area of $4 \times 9 \mathrm{~km}$. near "Byrd Station" the surface features and bottom topography were mapped in detail, and there was no obvious connection; some surface features on the scale of from $I \mathrm{~km}$. to $20 \mathrm{~km}$. were not reflected at all in the subglacial topography.

\section{DISGUSSION OF DR. G. R. BENTLEY'S PAPER}

Dr. J. F. Nye: Would it not be valuable to do this sort of thing on a larger scale from data that already exists? For example by taking a surface contour map of West Antarctica, or indeed even the whole of Antarctica, and the contour maps of the bed, and simply putting them together, you could obtain another map of variation of shear stress on the bottom.

Dr. Bentley: Yes, I think it probably would, but at any particular point a map of the whole of Antarctica does not give you a very good representation. On a small scale there is apparently no correlation between surface slope and ice thickness. On a larger scale there would be a better correspondence with a much more limited range in the values of the stress computed-but if you average over half a continent of course the result is going to be within a nice, narrow range. In this part of Antarctica the bottom is very jagged, and the map of the whole area will average over these so that at any particular point you could be off in ice thickness by $\mathrm{I}, 000 \mathrm{~m}$. or something like that. It seemed to be better to use actual individual ice thicknesses at a given point.

Dr. NyE: One would be very interested in the pattern of variation. If for instance one found the shear stress was large at the edges and small in the middle, or if there was an east-west variation, or something like that, it would be interesting. Of course it would vary less than your small scale values.

DR. G. DE Q. RoBIN: The general pattern you have shown is similar to the general pattern of variation we found at Maudheim, but I would agree with Dr. Nye. Before the I.G.Y. one looked at the map of West Antarctica and thought the surface was generally lower, and that the ice was probably very thick there with the rock surface well below sea-level. This more or less lines up with the general ideas that Dr. Nye has been putting forward. I am not entirely convinced that, on the evidence you have shown us, you can say that there is no relation between bottom and surface topography, particularly if you specify that your surface slope should be measured over distances of several times the thickness.

Dr. Bentley: Our features are on a scale several times the ice thickness. In a number of places we found basins where we had shots to the horizon going up in all directions over a distance of a few kilometres. It is quite unlikely that the surface slope here is measuring the direction of ice flow. Obviously the basin would not last very long!

Mr. J. T. Hollin: One would not expect the shear stress to be constant, one would expect low shear stress in areas of low velocity and high shear stress in areas of high velocity.

DR. BEnTLey: The places were separated by distances of only a few kilometres. 
DR. M. F. MeIer: What do you think might cause these irregularities on the surface?

DR. Bentley: I do not know what could cause them. I certainly expected the surface topography to show up in the bottom; I was very surprised when we could not find anything. These features are out in the open, there is no reason to expect any strange wind patterns to maintain features of this type. They do not appear to have any regular ridge and trough form; they seem to be any shape you might imagine. So I am afraid that, as far as what causes them, I do not have an opinion.

DR. W. H. WARD: Have you any idea whether this surface topography is maintained over any long period?

Dr. Bentley: No, I am afraid not. At "Byrd Station" this could be found out if you could relocate the flags, which I am afraid are lost. We could at least find the area again, but I do not know whether we could find a stake to tie down the positions and remeasure them at some time in the future. We did intend to do that in our original plan, but in the intervening years the stakes were lost.

DR. NYE: If this pattern were not stationary, if you went back in $20 \mathrm{yr}$. time and found it was different, this would be a very peculiar state of affairs, would it not? Because either it would have shifted by drifting, which would make nonsense of a lot of accumulation measurements, or the whole structure would have had to deform plastically to get rid of these bumps and put them elsewhere, which seems very unlikely.

Dr. Bentley: I do not know how we could measure if they were moving relative to the bottom or some place deeper in the ice. If they were like dunes, say, how would you measure the movement? What would you measure their movement relative to?

DR. NYE: If they were something like dunes, it would surely show up in the stratigraphy, would it not?

Dr. Bentley: The glaciologists dug a few pits in this area, but as far as I know they did not find any evidence of anything like dunes.

DR. J. W. GLEN: In interpreting these results it looks as though there are only two possibilities. One is the one we have just been discussing, that these things are features which are caused originally by wind or some other surface agent, nothing to do with what is underneath, and are moving about in a random way. On the other hand I suppose they could mean that the ice flow in this whole area is in fact extremely small. If the shear stresses that we find are not sufficient to cause an appreciable amount of flow, then of course you would not expect to find any correlation between what goes on on the surface and what goes on underneath; you are simply dealing with an ice sheet which is getting slowly thicker, and the surface shape is simply due to random factors in the accumulation. The features would move about, but only because of changes in accumulation. Deep down the old surface would still be where it was. This seems to me another possible explanation which has not been mentioned so far, and in view of the unlikelihoods which have been pointed out in the other explanations I think we ought to consider it.

Dr. Bentley: My answer would be that this evidence is over a considerable area. One traverse runs from "Byrd Station" almost to the Amundsen Sea, where the surface ice patterns show that there is a major outflow from West Antarctica into the Ross Ice Shelf and the Amundsen Sea (and not into the Bellingshausen Sea). The traverse ran very close to the Amundsen Sea almost all the way to the Bellingshausen Sea.

DR. GLEN: It seems to me that these features are of such a scale that, if the ice were flowing fairly fast, they would in fact cause variations in the flow. One would not expect a barchan on the surface to affect the flow of the Antarctic Ice Sheet at depth, simply because the scale is too small compared with the depth, but these things are of the same sort of scale as the depth 
and one would expect them therefore to affect the flow even if their origin is unconnected with the bed. They would thus be self-destructive due to the flow they would cause unless there were some meteorological explanation for their build-up-and the fact that they are there rather suggests to me that flow is not very rapid.

Dr. NyE: Could I just add this ingredient to what Dr. Glen has said, that perhaps the temperature is so low that shear stresses up to 2 bars would not do the trick?

Dr. Bentley: It does cut off quite sharply when you get a little over 2 bars. I did not find anything anywhere that goes over that.

Dr. NyE: If it were over that the ice would have flowed and stopped it.

Dr. Robin: The answer to Dr. Glen's earlier point that the ice over the whole area might not be flowing at all is to be found in the point that was made earlier that if you draw contours over the whole area at $200 \mathrm{~m}$. intervals and look at the map then you do get the impression of a general form that you feel would be flowing - the wide scale does give an impression of flowing.

\section{CLOSING REMARKS}

Dr. G. DE Q. Robin (Chairman): Before closing this symposium formally I would just like to say that those of us in Great Britain and Cambridge particularly have been very aware of missing Vaughan Lewis at a symposium like this. You may like to know that in the Geography Department, Cambridge University, we are starting up a Memorial Fund for Vaughan Lewis, the purpose of which will not be decided until we see the response. If any of those who knew him would like to contribute, I can let them have details.

Now it is my pleasure to thank everyone, and particularly all who came from overseas, for making the long journey to this Symposium and anniversary celebrations and for taking part in our discussions. Of course we must thank particularly those who have contributed papers to the meeting, and my fellow chairmen, Dr. B. Fristrup and Mr. W. O. Field.

Our general speeches were given last night, but I do not think we can let this occasion pass without thanking Hilda Richardson for everything she did to lay on the organization here with a number of helpers, whom I will not mention by name except for George Elliston who has put the exhibition of photographs together in the Scott Polar Research Institute.

Mr. G. Seligman: I just want to thank Dr. Robin for having taken charge of this meeting; the various chairmen who have deputized for him he has thanked already. I also want to thank him very much for having made the arrangements for us to come here to the Department of Geography for these meetings. 